\title{
Preliminary analysis of the care of injured patients in 33 British hospitals: first report of the United Kingdom major trauma outcome study
}

\author{
D W Yates, $M$ Woodford, S Hollis
}

\begin{abstract}
Objective-To measure the effectiveness of management of major trauma in the United Kingdom.

Design-Review of the care of all seriously injured patients seen over two years.

Setting-33 hospitals which receive patients who have sustained major trauma.

Subjects-14648 injured patients admitted for more than three days, transferred or admitted into an intensive care bed, or dying from their injuries.

Main outcome measure-Death or survival in hospital within three months of the injury.

Results $-21 \%$ of seriously injured patients (1299) took longer than one hour to reach hospital. Time before arrival at hospital was not related to severity of injury. A senior house officer was in charge of initial hospital resuscitation in 57\% (826/1445) of patients with an injury severity score $\geqslant 16$. More senior staff were commonly responsible for definitive operations, but only $46 \%(165 / 355)$ of patients judged to require early operation arrived in theatre within two hours. Mortality for 6111 patients sustaining blunt trauma and treated in the 14 busiest hospitals was significantly higher (actual 408, predicted 295.6, $p<0.001$ ) than in a comparable North American dataset. Large differences in the 14 hospitals assessed could not be explained by variations in case load or facilities. In contrast, the outcome of the $4 \cdot 1 \%(597)$ of patients with penetrating injuries was better than that of a comparable group in the United States. Analysis of the 415 penetrating injuries with complete data showed that 15 patients died (19.3 predicted; $p=0.04$ ).

Conclusions-The initial management of major trauma in the United Kingdom remains unsatisfactory. There are delays in providing experienced staff and timely operations. Mortality varies inexplicably between hospitals and, for blunt trauma, is generally higher than in the United States.
\end{abstract}

\section{Introduction}

The dominant position of trauma as the leading cause of death in the first four decades of life is well established. Many young people survive but with serious disabilities, and of course the consequences of accidental and intentional injury are evident at all ages. The potential for significant reduction in morbidity and mortality associated with "accidents" and the relative ease with which this could be measured is acknowledged in the Department of Health publication The Health of the Nation. ${ }^{1}$ Many lives are thought to be lost as a direct result of failure to provide adequate care of the injured. Many consider that the system rather than any one of its component parts is primarily at fault in this respect.
The characteristics of an ideal trauma service in Britain (and, indeed, whether one model is appropriate for the entire country) have yet to be determined. Several initiatives were proposed in the recent report of the working party on the management of patients with major injuries convened by the Royal College of Surgeons of England. ${ }^{2}$ The report acknowledged that a prospective study using injury severity scoring systems would be necessary if its recommendations were to be scientifically evaluated. This would provide the comparative evidence on which to base a decision as to the most appropriate systems of trauma care. In short, it recommended the adoption of an auditing system similar to the one pioneered by the Washington Hospital Center in the United States. ${ }^{3}$

\section{DEVELOPMENT OF TRAUMA AUDIT}

There is increasing awareness of the importance of collaborative reviews of trauma care, especially between the accident and emergency department and inpatient specialties such as general surgery, orthopaedic surgery, neurosurgery, and intensive care. Interdisciplinary clinical meetings are of little value, however, if they only result in an exchange of anecdotes. The process of care can be assessed objectively only if input and output are known - that is, if the severity of the anatomical injury and the physiological response is matched against outcome. Additionally, comparisons between centres or over time can be made only if similar data are collected and analysed in a consistent manner. This process can provide a statistical base to audit and allow some measure of performance. There is understandable caution about such an approach and a healthy scepticism of the validity of the analyses. The dependence on death or survival as the only outcome measure is a particular concern; there is, however, no generally accepted method of measuring disability. ${ }^{4}$ Nevertheless the concept of case analysis and assessment of institutions on the basis of statistics rather than dogma has, in general, been well received.

\section{DEVELOPMENT OF INJURY SCORING SYSTEMS}

The origins of scoring systems have been described. The abbreviated injury scale (AIS) is now the most widely used measure of severity of anatomical injury It scores from 1 (minor) to 6 (fatal) over 1200 injuries (see acknowledgments for availability). Patients with multiple injuries are scored by adding together the squares of the highest scores in up to three regions of the body. This is the injury severity score (ISS), which ranges from 1 to $75\left(5^{2}+5^{2}+5^{2}\right)$. A patient with an AIS 6 injury in any body region is, by convention, given a score of $75 . .^{7}$

Many systems have been developed to measure physiological derangement. The revised trauma score (RTS) is currently in widespread use. It combines 
respiratory rate, systolic blood pressure, and Glasgow coma scale score. Their relative contributions to the overall score are weighted according to their ability to predict mortality, as determined by their application to a large North American dataset. Although calculating the score seems complex, simple computer programs are available to help. The revised trauma score ranges from 0 (dead) to $7 \cdot 84$ (normal). ${ }^{8}$

Physiological derangement and anatomical injury are the most important determinants of the threat to life, but age and the method of wounding (blunt or penetrating) are also relevant. Boyd et al combined these four elements to provide a measure of the

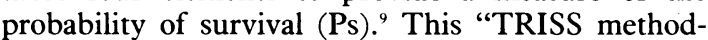
ology" (box) formed the statistical basis for the major trauma outcome study developed by the Washington Hospital Center. ${ }^{1011}$

This paper summarises the results of the first two years' work of the United Kingdom major trauma outcome study, in which data on almost 15000 injured patients have been collected and analysed.

\section{Method}

Information is collected on all injured patients who are admitted to hospital for more than three days, die from their injuries, are transferred to or from another hospital for further care, or are admitted to a high dependency or intensive care unit. Glasgow coma scale score, blood pressure, and respiratory rate are recorded as the patient enters the accident and emergency department. A comprehensive list of injuries is made for subsequent calculation of the injury severity score. Other components of the study include an assessment of care before arrival at the hospital, in the emergency department, in intensive care, and in the operating theatre. This is aided by recording the times of patient movement through the departments and the seniority of doctors involved and the time of their attendance. Pre-existing diseases, complications, subsequent operations, and outcome are also noted. In those who survive, the nature of temporary or permanent disability is estimated either at hospital discharge or three months after the injury, whichever is the earlier. All this information is sent to the North Western Injury Research Centre in Manchester either on the single A4 recording card or on disk.

Elderly patients with isolated fractures of the femoral neck made up $1-32 \%$ of cases submitted by participating hospitals. The American reference database also contains such cases, again with considerable variation between the numbers submitted by different institutions. The larger centres (including all 26 level 1 centres in Pennsylvania) have not returned data on these patients to the Trauma Research Center at the Washington Hospital Center, Washington, DC, since 1987. Removing these patients from the British database improves the overall value of the $M$ statistic from 0.91 to 0.94 , suggesting that there was a disproportionate number of cases in the database. The analyses presented below therefore exclude patients with isolated femoral neck fractures.

Summary tables comparing the TRISS data of all participating hospitals have been compiled, but no individual in the injury research centre has the complete key to this coded information. Each hospital knows its own code and can therefore judge its own position in these national "league tables." Additionally, to aid local audit, lists of individual cases fulfilling certain criteria are supplied to participating hospitals.

\section{STATISTICS}

The $M$ statistic has been fully described by Smith et $a l^{10}$; it compares the distribution of the predicted
TRISS method of determining probability of survival

$$
\begin{aligned}
& \qquad P_{s}=\frac{1}{1+e^{-b}} \\
& \text { where } b=b_{0}+b_{1}(\text { RTS })+b_{2}(\text { ISS })+b_{3}(A) \\
& \text { For blunt trauma: } b_{0}=-1 \cdot 2470 b_{1}=0.9544 \\
& b_{2}=-0.0768 b_{3}=-1.9052 \\
& \text { For penetrating trauma: } b_{0}=-0.6029 b_{1}=1 \cdot 1430 \\
& b_{2}=-0.1516 b_{3}=-2.6676
\end{aligned}
$$

$\mathrm{RTS}=$ revised trauma score; ISS = injury severity score; $A=0$ if age $\leqslant 54$ years, 1 if $\geqslant 55$ years.

survival probabilities in a sample population with that of the main database. The nearer $M$ is to $1 \cdot 0$, the better the fit. A value over 0.88 is considered acceptable. The W statistic is the difference between actual and predicted numbers of survivors per 100 patients, and the $\mathrm{Z}$ statistic measures the significance of $\mathrm{W}$. These scores have been described in detail elsewhere. ${ }^{10} 11$

Statistical analysis was performed with the statistical package for the social sciences. ${ }^{12}$ Association between patient management and outcome was measured by Spearman rank correlation coefficient $\left(r_{s}\right)$ for continuous data and $\chi^{2}$ tests for categorical data.

\section{Results}

Currently, 47 hospitals in England and Wales participate in the study. The following analyses are based on the details of 14648 patients from 33 hospitals which were held on computer at the end of December 1991. Overall 597 patients $(4 \cdot 1 \%)$ sustained penetrating injuries. Of the 14051 patients with blunt injuries, $3998(28.5 \%)$ had been involved in a road traffic accident, $472(3.4 \%)$ had been assaulted, $8296(59.0 \%)$ had sustained injury while falling, and other causes of blunt injury totalled $1285(9 \cdot 1 \%)$. Of those who had fallen, $3306(39.9 \%)$ were elderly patients who had an isolated fracture of the femoral neck; $83.0 \%$ (2746) of these were women. The peak incidence in women is in the eighth and ninth decades; in men, in the second and third decades. Patients aged over 65 admitted with an isolated femoral neck fracture were excluded; thus the following analyses are based on 11342 patients.

Table I shows the distribution of the revised trauma score and the injury severity score and their relation with mortality. Mortality was lower in patients with insufficient information to calculate a revised trauma score, compared with all others $(4.9 \%$ (149/3044) $v$ $\left.6 \cdot 8 \%(565 / 8298), \chi^{2}{ }_{1}=13 \cdot 86, p=0.0002\right)$. Mortality of patients for whom insufficient data were available to calculate the injury severity score was $4.9 \%(7 / 143)$ compared with $6 \cdot 3 \%(707 / 11199)$ for all other patients $\left(\chi_{1}^{2}=0 \cdot 51, p=0 \cdot 48\right)$.

TABLE I-Relation of scores of severity of injuries to mortality three months after injury

\begin{tabular}{lccc}
\hline & $\begin{array}{c}\text { No(\%) } \\
\text { surviving }\end{array}$ & $\begin{array}{c}\text { No(\%) } \\
\text { dying }\end{array}$ & Total \\
\hline Revised trauma score: & & & \multicolumn{2}{c}{8298} \\
$<1 \cdot 00$ & $3(3)$ & $98(97)$ & 101 \\
$1 \cdot 00<2 \cdot 00$ & $2(17)$ & $10(83)$ & 12 \\
$2 \cdot 00<3 \cdot 00$ & $11(31)$ & $25(69)$ & 36 \\
$3 \cdot 00<4 \cdot 00$ & $25(48)$ & $27(52)$ & 52 \\
$4 \cdot 00<5 \cdot 00$ & $167(66)$ & $85(34)$ & 252 \\
$5 \cdot 00<6 \cdot 00$ & $288(75)$ & $94(25)$ & 382 \\
$6 \cdot 00<7 \cdot 00$ & $328(89)$ & $39(11)$ & 367 \\
$7 \cdot 00-7 \cdot 84$ & $6909(97)$ & $187(3)$ & 7096 \\
Injury severity score & & & \multicolumn{2}{c}{11199} \\
$1-8$ & $4926(98)$ & $93(2)$ & 5019 \\
$9-15$ & $4310(98)$ & $69(2)$ & 4379 \\
$16-24$ & $766(87)$ & $117(13)$ & 883 \\
$25-40$ & $436(63)$ & $255(37)$ & 691 \\
$41-49$ & $33(35)$ & $62(65)$ & 95 \\
$50-66$ & $19(20)$ & $76(80)$ & 95 \\
75 & $2(5)$ & $35(95)$ & 37 \\
\hline
\end{tabular}


Table II represents the "league table" of performance of 14 hospitals that returned information on more than 100 patients and in which the case mix, as determined by the $M$ statistic, was judged to be similar to that in the original American dataset. The table is compiled in descending order of the W statistic, which provides a measure of performance per 100 patients treated. In seven hospitals the statistics show a significantly inferior standard of clinical care $(Z<-1.96)$, and in another six the results are not statistically different from the American norm. Only one hospital returned data that suggests a standard of care significantly better than the American average. Participating hospitals have also been categorised according to facilities; analysis of $\mathrm{W}$ statistics did not show any association between hospitals' positions in the league table and the provision of neurosurgical facilities or the immediate availability of operating theatres and senior surgeons (unpublished data).

The 597 penetrating injuries accounted for $4 \cdot 1 \%$ of total injuries. In most hospitals the number of penetrating injuries was small, ranging from one to 98 . In the whole study group four patients $(0 \cdot 7 \%)$ with penetrating injuries whose probability of survival was calculated to be over $50 \%$ died, and six patients $(1.0 \%)$ who had a probability of survival of less than $50 \%$ survived. Overall, the British group with penetrating injuries seemed to be comparable, in terms of injury severity, to the American dataset $(M=0.91)$, and the outcome was significantly better (actual deaths 15 , predicted deaths $19 \cdot 3$, in the 415 penetrating injuries with complete data; $W=1 \cdot 03 ; Z=2 \cdot 02, p=0 \cdot 04$ ).

In 4119 cases the duration of care before hospital

TABLE II-Management of blunt trauma in 14 British hospitals

\begin{tabular}{|c|c|c|c|c|c|c|}
\hline \multirow[b]{2}{*}{ Hospital } & \multirow{2}{*}{$\begin{array}{c}\text { No of } \\
\text { patients }\end{array}$} & \multicolumn{2}{|c|}{ No of survivors } & \multirow{2}{*}{$\underset{\text { statistic }^{\star}}{\mathrm{W}}$} & \multirow{2}{*}{$\underset{\text { statisticf }}{\mathrm{Z}}$} & \multirow[b]{2}{*}{$\mathrm{p}$ Valu } \\
\hline & & Actual & Predicted & & & \\
\hline 1 & 406 & 400 & $389 \cdot 1$ & 2.69 & 3.23 & 0.001 \\
\hline 2 & 804 & 773 & $777 \cdot 4$ & -0.55 & $-1 \cdot 12$ & $0 \cdot 26$ \\
\hline 3 & 600 & 579 & $582 \cdot 4$ & -0.57 & -1.02 & $0 \cdot 31$ \\
\hline 4 & 113 & 102 & $102 \cdot 8$ & -0.75 & -0.55 & 0.58 \\
\hline 5 & 212 & 201 & $203 \cdot 1$ & -1.01 & -1.05 & $0 \cdot 29$ \\
\hline 6 & 840 & 766 & $778 \cdot 2$ & $-1 \cdot 45$ & $-2 \cdot 34$ & 0.02 \\
\hline 7 & 156 & 145 & 147.5 & -1.63 & $-1 \cdot 16$ & 0.25 \\
\hline 8 & 186 & 161 & 165.3 & $-2 \cdot 33$ & -1.82 & 0.07 \\
\hline 9 & 379 & 358 & $366 \cdot 8$ & $-2 \cdot 33$ & $-3 \cdot 46$ & 0.001 \\
\hline 10 & 366 & 346 & 355.0 & $-2 \cdot 46$ & $-3 \cdot 30$ & 0.001 \\
\hline 11 & 538 & 511 & 524.6 & $-2 \cdot 53$ & $-4 \cdot 49$ & $<0.001$ \\
\hline 12 & 319 & 276 & $288 \cdot 1$ & $-3 \cdot 80$ & $-3 \cdot 43$ & $<0.001$ \\
\hline 13 & 356 & 331 & $345 \cdot 3$ & -4.02 & $-5 \cdot 45$ & $<0.001$ \\
\hline 14 & 836 & 754 & $789 \cdot 5$ & $-4 \cdot 25$ & $-7 \cdot 13$ & $<0.001$ \\
\hline Total & 6111 & 5703 & $5815 \cdot 4$ & -1.84 & $-9 \cdot 18$ & $<0.001$ \\
\hline
\end{tabular}

$\star W=($ Actual - predicted survivors $) /$ No of patients $\times 100$.

$+\mathrm{Z}=\mathrm{W} / \mathrm{S}$ tandard error of $\mathrm{W}$.

TABLE III - Time between injury and arrival at hospital. Values are numbers (percentages)

\begin{tabular}{lcccccrr}
\hline & \multicolumn{7}{c}{ Injury severity score } \\
\cline { 2 - 7 } Interval & $1-8$ & $\begin{array}{c}9-15 \\
(\mathbf{n}=1721)\end{array}$ & $\begin{array}{c}16-24 \\
(\mathrm{n}=1779)\end{array}$ & $\begin{array}{c}25-40 \\
(\mathbf{n}=319)\end{array}$ & $\begin{array}{c}41-49 \\
(\mathbf{n}=216)\end{array}$ & $\begin{array}{c}50-75 \\
(\mathbf{n}=56)\end{array}$ & $\begin{array}{c}\text { Total } \\
(\mathbf{n}=4119)\end{array}$ \\
\hline$\leqslant 15$ Minutes & $164(10)$ & $173(10)$ & $42(13)$ & $31(14)$ & $4(14)$ & $7(13)$ & $421(10)$ \\
$>15 \leqslant 30$ Minutes & $318(19)$ & $409(23)$ & $90(28)$ & $60(28)$ & $12(43)$ & $18(32)$ & $907(22)$ \\
$>30 \leqslant 60$ Minutes & $600(35)$ & $668(38)$ & $111(35)$ & $81(38)$ & $6(21)$ & $26(46)$ & $1492(36)$ \\
$>1 \leqslant 2$ Hours & $306(18)$ & $281(16)$ & $49(15)$ & $28(13)$ & $5(18)$ & $3(5)$ & $672(16)$ \\
$>2$ hours & $333(19)$ & $248(14)$ & $27(8)$ & $16(7)$ & $1(4)$ & $2(4)$ & $627(16)$ \\
Missing data & 2923 & 2427 & 452 & 362 & 50 & 54 & 6268 \\
\hline
\end{tabular}

TABLE IV-Grade of doctor in charge of initial resuscitation of patients with injury severity score $\geqslant 16$. Values are numbers (percentages)

\begin{tabular}{lccccc}
\hline & \multicolumn{5}{c}{ Injury severity score } \\
\cline { 2 - 6 } Grade of doctor & $\begin{array}{c}16-24 \\
(\mathbf{n}=719)\end{array}$ & $\begin{array}{c}25-40 \\
(\mathbf{n}=547)\end{array}$ & $\begin{array}{c}41-49 \\
(\mathbf{n}=77)\end{array}$ & $\begin{array}{c}50-75 \\
(\mathbf{n}=102)\end{array}$ & $\begin{array}{c}\text { Total } \\
(\mathbf{n}=1445)\end{array}$ \\
\hline Consultant or senior registrar & $162(23)$ & $157(29)$ & $30(39)$ & $36(35)$ & $385(27)$ \\
Registrar & $97(13)$ & $102(19)$ & $12(16)$ & $23(23)$ & $234(16)$ \\
Senior house officer & $460(64)$ & $288(53)$ & $35(45)$ & $43(42)$ & $826(57)$ \\
\hline
\end{tabular}

TABLE $\mathrm{v}-$ Time between arrival in accident and emergency department and arrival in theatre. Values are numbers (percentages)

\begin{tabular}{lccccc}
\hline & \multicolumn{5}{c}{ Injury severity score } \\
\cline { 2 - 6 } Time interval & $\begin{array}{c}16-24 \\
(\mathbf{n}=271)\end{array}$ & $\begin{array}{c}25-40 \\
(\mathbf{n}=228)\end{array}$ & $\begin{array}{c}41-49 \\
(\mathbf{n}=30)\end{array}$ & $\begin{array}{c}50-75 \\
(\mathbf{n}=33)\end{array}$ & $\begin{array}{c}\text { Total } \\
(\mathbf{n}=562)\end{array}$ \\
\hline \$2 Hours & $60(22)$ & $74(32)$ & $13(43)$ & $18(55)$ & $165(29)$ \\
2-4 Hours & $45(17)$ & $53(23)$ & $10(33)$ & $8(24)$ & $116(21)$ \\
4-6 Hours & $26(10)$ & $19(8)$ & $4(13)$ & $3(9)$ & $52(9)$ \\
6-8. Hours & $10(4)$ & $12(5)$ & 0 & 0 & $22(4)$ \\
$>8$ Hours & $130(48)$ & $70(31)$ & $3(10)$ & $4(12)$ & $207(37)$ \\
\hline
\end{tabular}

(difference between time of injury and time of arrival at hospital) was known. Table III shows its relation to injury severity score. Patients transferred for further care of their injuries were not included in this analysis. In general, shorter time before hospital was weakly associated with an increased score $\left(r_{s}=0 \cdot 15\right.$, $\mathrm{p}<0.0001)$. In $21 \%(131 / 619)$ of patients with a score above 15 , more than 60 minutes elapsed between the time of the incident and arrival at hospital.

Table IV shows the grade of doctor in charge of the initial resuscitation of $1445(80 \%)$ patients with an injury severity score of 16 or greater. Data on 356 patients were not available. Increasing injury severity and seniority of doctor present were positively correlated $\left(r_{s}=0 \cdot 16, p<0 \cdot 001\right)$, but senior house officers were most commonly in charge of resuscitation at all injury severities.

The speciality of the most senior doctor in the resuscitating team was determined for those patients with an injury severity score $>15$. In $38 \%$ of cases (393/ $1045)$ the most senior doctor was from the accident and emergency department, in 6\% (66) from the orthopaedic department, $7 \%(69)$ from the general surgical department, $6 \%$ (62) from the neurosurgical department, and 4\% (37) from the anaesthetic department. In $23 \%$ (244) of cases more than one speciality was represented as the most senior rank, and in $16 \%$ (167) the specialty was not recorded. In $1 \%$ (seven) the most senior doctor was recorded as a trauma specialist.

For $562(70 \%)$ patients with an injury severity score $\geqslant 16$ the time between arrival in the accident and emergency department and their transfer to the operating theatre was recorded. Table $\mathrm{V}$ shows the relation between this time and the severity of injury. The median delay for those patients arriving in theatre more than eight hours after presenting to the department was $39 \cdot 5$ (range 8-1467) hours, suggesting that this delay was planned, secondary to care elsewhere. Of those judged to require early operation (within the first eight hours), only $46 \%$ (165) were taken to theatre within two hours. There was a tendency, however, for more seriously injured patients to have shorter delays $\left(r_{s}=-0 \cdot 19, p<0 \cdot 001\right)$. The seniority of the surgeon was known in 318 of the patients with a score $\geqslant 16$ who had an operation within eight hours of the accident (table VI). In 284 cases the seniority of the anaesthetist was known (table VII). Senior surgeons and anaesthetists were the most frequently represented groups at nearly all operations and were increasingly represented in cases with more serious injury (surgeons $r_{s}=0 \cdot 16$, $\mathrm{p}=0.002$; anaesthetists $\left.\mathrm{r}_{\mathrm{s}}=0.21, \mathrm{p}<0.001\right)$.

\section{Discussion}

This is the first report of the work of the major trauma outcome study in the United Kingdom. The task of collecting data on prehospital care, emergency admission, and outcome has been difficult for the 33 participating hospitals. Inclusion of patients with fractures of the femoral neck was a particular burden which did not contribute greatly to the value of the study. These patients were included initially because they seemed to fulfil the entry requirements for the 
TABLE VI-Seniority of surgeon in cases arriving in theatre within eight hours of hospital admission. Values are numbers (percentages)

\begin{tabular}{lccccc}
\hline & \multicolumn{5}{c}{ Injury severity score } \\
\cline { 2 - 6 } Grade of surgeon & $16-24$ & $\begin{array}{c}25-40 \\
(\mathbf{n}=127)\end{array}$ & $\begin{array}{c}41-49 \\
(\mathbf{n}=142)\end{array}$ & $\begin{array}{c}50-75 \\
(\mathbf{n}=25)\end{array}$ & $\begin{array}{c}\text { Total } \\
(\mathbf{n}=318)\end{array}$ \\
\hline Consultant or senior registrar & $74(58)$ & $91(64)$ & $22(88)$ & $19(79)$ & $206(65)$ \\
Registrar & $43(35)$ & $45(32)$ & $3(12)$ & $4(17)$ & $97(31)$ \\
Senior house officer & $8(6)$ & $6(4)$ & 0 & $1(4)$ & $15(5)$ \\
\hline
\end{tabular}

TABLE VII - Seniority of anaesthetist in cases arriving in theatre within eight hours of hospital admission. Values are numbers (percentages)

\begin{tabular}{lccccc}
\hline & \multicolumn{5}{c}{ Injury severity score } \\
\cline { 2 - 6 } Grade of anaesthetist & $\begin{array}{c}16-24 \\
(\mathbf{n}=113)\end{array}$ & $\begin{array}{c}25-40 \\
(\mathbf{n}=130)\end{array}$ & $\begin{array}{c}41-49 \\
(\mathbf{n}=20)\end{array}$ & $\begin{array}{c}50-75 \\
(\mathbf{n}=21)\end{array}$ & $\begin{array}{c}\text { Total } \\
(\mathbf{n}=284)\end{array}$ \\
\hline Consultant or senior registrar & $45(40)$ & $74(57)$ & $13(65)$ & $19(90)$ & $151(53)$ \\
Registrar & $48(42)$ & $37(29)$ & $7(35)$ & $1(5)$ & $93(33)$ \\
Senior house officer & $20(18)$ & $19(15)$ & 0 & $1(5)$ & $40(14)$ \\
\hline
\end{tabular}

major trauma outcome study in the United States and therefore allow comparison of the two datasets. However, such patients are more often admitted through emergency departments in the United Kingdom than 'in the United States, where many are admitted by other routes. In July 1991 it was therefore decided to stop collecting data on patients with isolated fractures of the femoral neck.

The data collection and coding system has been centralised to provide consistency in injury severity scoring. Many case records were, however, returned incomplete, the commonest omission being the recording of the respiratory rate, a component of the revised trauma score. There was a surprising variation between hospitals: completeness of data for the revised trauma score varied from $41 \cdot 3 \%$ to $100 \%$ of cases. It is hoped that courses which have been established on injury scaling and data collection will lead to an improvement in the quality of returned data. More support from newly established audit departments should also help.

The age and sex profile of patients on the database is similar to that reported by the Office of Population Censuses and Surveys, ${ }^{13}$ and the mortality for patients with incomplete data is similar to that of fully documented patients. It would seem reasonable, therefore, to assume that the results from the 33 centres in the study will have a wider relevance.

The injury severity score and the revised trauma score are imprecise tools, but the TRISS methodology is in widespread use as a method of assessing overall mortality. Our data show that reduced revised trauma scores and increased injury severity score are associated with greater mortality. The TRISS methodology has not identified the cause of the differences among British hospitals but it does suggest that, in general, the standard of care of patients with serious blunt injuries is not as high as it is in the United States. No such distinction can be made for patients with penetrating injuries. The difference could reflect the more obvious injuries to the latter group and the occult nature of many blunt injuries, further emphasising the acknowledged deficiencies in initial assessment of these patients.

Many participating hospitals were unable to provide information on journey times - just one example of the inadequate integration of trauma services in the United Kingdom. Table III is based on the $36 \%$ of cases where these data were supplied and shows long intervals before many seriously injured patients reach hospital. The trend to increasing mortality in the groups of most severely injured patients underlines the importance of recent initiatives to improve the quality and control of out of hospital care.

Table IV shows that the initial resuscitation of most trauma patients continues to be managed by relatively junior doctors. Not surprisingly, the most senior doctor was usually from the accident and emergency department and relatively infrequently from surgery and anaesthesia. In contrast, senior registrars and consultants from these specialities were involved mainly in the operative management of the more seriously injured patients (tables VI and VII). The limited information available suggests that there is a considerable delay between arrival in hospital and first operation (table V).

Despite the size of the study, examination of some aspects of trauma care have not been possible because of inadequacies of data collection. Modifications of the system have been introduced, and as the study population continues to expand more detailed statistical analyses will be undertaken. The statistical method itself will also be reviewed. In particular, improvements will be sought in the method of assessing physiological derangements in individual patients and in the measurement of overall differences between participating hospitals. However, the preliminary results contain sufficient information to initiate informed discussion on the components of a comprehensive trauma service in the United Kingdom.

We thank the Department of Health and the North Western Regional Health Authority for financial support and Gwyneth Turner and Mo Macrae for their help in computation and administration.

Copies of the abbreviated injury scale are available from $\mathrm{M}$ Woodford, North Western Injury Research Centre, Clinical Sciences Building, Hope Hospital, Salford M6 8HD

Hospitals participating in this study: Addenbrooke's Hospital, Cambridge; Basildon Hospital, Essex; Bolton Royal Infirmary, Bolton; Bristol Royal Infirmary, Bristol; Bury General Hospital, Bury; Countess of Chester Hospital, Chester; Coventry and Warwickshire Hospital, Coventry; Craigavon Area Hospital, County Armagh; Hope Hospital, Salford; Homerton Hospital, London; Hull Royal Infirmary, North Humberside; Ipswich District General Hospital, Ipswich; Kent and Canterbury General Hospital, Canterbury; King's College Hospital, London; Leeds General Infirmary, Leeds; Middlesborough General Hospital, Middlesborough; Northern General Hospital, Sheffield; North Staffordshire Royal Infirmary, Stoke on Trent; Pinderfields General Hospital, Wakefield; Royal Lancaster Infirmary, Lancaster; Royal London Hospital, London; Royal Preston Hospital, Preston; Royal Sussex County Hospital, Brighton; St Bartholomew's Hospital, London; St James's University Hospital, Leeds; St Mary's Hospital, London; Stockport Infirmary, Stockport; Southampton General Hospital, Southampton; Tameside General Hospital, Ashton under Lyne; Victoria Hospital, Blackpool; Wexham Park Hospital, Slough; Withington Hospital, Manchester; Worcester Royal Infirmary, Worcester.

1 Department of Health. The Health of the Nation. London: HMSO, 1991. (CMD 1523.)

Royal College of Surgeons of England. Report of the working party on the management of patients with major injuries. London: RCS, 1988.

3 Champion HR, Copes WS, Sacco WJ, Lawnwick MM, Keast SL, Bain LW, et al. The major trauma outcome study: establishing national norms for et al. The major trauma outcome study:
trauma care. T Trauma 1990;30:1356-65.

4 Yates DW, Heath DF, Mars E, Taylor RJ. A system for measuring the severity of temporary and permanent disability after injury. Accid Anal Prev 1991;23:323-9

5 Yates DW. Injury scoring systems. Intensive Therapy and Clinical Monitoring 1990;10:38-44

6 Baker SP, O'Neill B, Haddon W, Long WB. The injury severity score: a method for describing patients with multiple injuries and evaluating emergency care. $\mathcal{F}$ Trauma 1974;14:187-96.

7 Baker SP, O'Neill B. The injury severity score: an update. $\mathcal{f}$ Trauma 1976;16:882-5

8 Champion HR, Sacco WJ, Copes WS, Gann DS, Gennarelli TA, Flanagan ME. A revision of the trauma score. I Trauma 1989;29:623-9.

9 Boyd CR, Tolson MA, Copes WS. Evaluating trauma care: the TRISS method. F Trauma 1987;27:370-8.

10 Smith EJ, Ward AJ, Smith D. Trauma scoring methods. Br $\mathcal{J}$ Hosp Med 1990;44:114-8.

11 Yates DW. Scoring systems for trauma. BMF 1990;301:1090-4.

12 SPSS. Inc. Chicago, USA.

13 Office of Population Censuses and Surveys. Mortality statistics: cause 1985. London: HMSO, 1986

(Accepted 22 fuly 1992) 